\title{
A fołografia em livros didáticos: entre provas e semelhanças.
}

\author{
The photography in textbooks: \\ among evidence and similarities.
}

João Batista Freitas Cardoso

Pós-Doutorado em Comunicação pela ECA-USP. Doutorado e Mestrado em Comunicação e Semiótica pela PUC/SP. Professor no Programa de Mestrado em Comunicação da Universidade Municipal de São Caetano do Sul. Professor nas Universidades Mackenzie e Santa Cecília.

\section{Cristiane Mayumi Morinaga}

PMestre em Comunicação pelo Programa de Pós-graduação em Comunicação da Universidade Municipal de São Caetano do Sul (PPGCOM/USCS)

\section{RESUMO}

Este artigo objetiva estudar o potencial de significação das fotografias em livros didáticos para o Ensino Fundamental. Utilizando como base a teoria semiótica de Charles Sanders Peirce, foi realizada uma análise comparativa entre fotografias publicadas em três diferentes edições de livros de História, de um único autor (Saber e Fazer História, Gilberto Cotrim, 1999; 2009; 2012). Com base nas análises, pudemos identificar os potenciais de significação dos diferentes tipos de fotografias.

Palavras-chave: fotografia; livro didático; semiótica peirciana.

\section{ABSTRACT}

This article aims to study the potential significance of the photographs in textbooks for the Elementary School. Using Charles Sanders Peirce's semiotic theory as base, it was performed a comparative analysis between photographs published in three different editions of History textbooks written by a single author (Saber e Fazer História, Gilberto Cotrim, 1999; 2009; 2012). Based on the analysis we identified the potential significance of the different types of pictures.

Keywords: photography; course books; peircean semiotics. 
Introdução

No final da década de 1990 e início de 2000 as publicações da lei de direitos autorais (Lei no 9.610, de 19 de fevereiro de 1998) e do Código Civil (Lei $\mathrm{n}^{\circ}$ 10.406, de 10 de janeiro de 2002) afetaram diretamente o mercado editorial e, em especial, o uso de fotografias em livros didáticos. As restrições ao uso de imagens de pessoas fizeram com que os profissionais da área (fotógrafos, iconógrafos e editores) buscassem alternativas para ilustrar os conteúdos das matérias. Uma das alternativas foi substituir as fotografias por desenhos, outra foi alterar a própria composição fotográfica - enquadramento, ângulo etc. É justamente esta última que interessa à pesquisa, pois partimos do princípio de que, mesmo quando se referem a um único objeto e se encontram em contextos similares, diferentes representações fotográficas podem gerar leituras e entendimentos distintos.

Tendo em vista esse pressuposto, o principal objetivo do presente artigo é investigar os potenciais de comunicação de diferentes fotografias, publicadas em livros didáticos, que visam exercer a mesma função. Para isso, foram analisadas três diferentes fotografias (publicadas nas edições de 1999, 2009 e 2012) que ilustram a mesma matéria (sobre o impeachment do ex-presidente Collor), do mesmo autor (Gilberto Cotrim), em uma mesma coleção (Saber e Fažer História, publicada pela Editora Saraiva), destinada a um único público (estudantes do último ano do Ensino Fundamental).

Convém considerar que, no material didático, a fotografia serve elemento de comunicação, como parte do processo de aprendizado (COSTA, 2013). Ou seja, ainda que se saiba que toda fotografia é um discurso com propósitos específicos, ela é incorporada ao material didático com o intuito de complementar o conteúdo de ensino e auxiliar no entendimento da matéria. Nesse sentido, a fotografia atua principalmente como registro ou documento: registro de pessoas, objetos e paisagens; documento que comprova um acontecimento.

Para realizar as análises fizemos uso das classes de signos de Charles S. Peirce, que entendemos auxiliar na identificação dos distintos potenciais de significação em cada proposta composicional. Por meio das análises foi possível observar os aspectos indiciais e icônicos que permitem à fotografia servir como elemento de comunicação: como registro, por meio da semelhança com a realidade que se pretende mostrar (aspecto icônico); e como prova (constatação documental) de que o objeto retratado de fato existiu (aspecto indicial). Contudo, percebemos que as opções feitas em virtude das restrições impostas pela legislação vigente ${ }^{1}$, alteram a relação da fotografia com o texto e, consequentemente, os potenciais interpretativos. 


\section{0 signo fotográfico no livro didático}

Conforme afirma Lúcia Santaella, a semiótica de Peirce "funciona como um mapa lógico que traça as linhas dos diferentes aspectos através dos quais uma análise deve ser conduzida" (2010, p. 6). Para a autora, sob a ótica peirciana, semiótica pode ser compreendida como sinônimo de lógica. Assim, as classificações sígnicas servem como padrões que abrangem todos os aspectos epistemológicos e ontológicos do universo dos signos.

Para Peirce (2012), um signo intenta representar alguma coisa para um conceito existente na mente de alguém. Dirigindo-se a essa pessoa, um primeiro signo criará na mente dela um signo equivalente a si mesmo ou, eventualmente, um signo mais desenvolvido. Este segundo signo, criado na mente desse intérprete, recebe a designação de interpretante, e a coisa representada é conhecida pela designação de objeto. Nesse sentido, qualquer mensagem visual pode ser compreendida como um signo que represente algo para alguém que já tenha em mente algum conceito sobre esse ou aquele objeto. No caso da fotografia em livro didático, acredita-se que a imagem funcione como signo a partir do momento que o estudante já tenha um conceito sobre o tema tratado - seja devido à leitura da matéria ou explicações do professor.

Considerando as relações entre o signo, o objeto e o interpretante, Peirce subdivide os signos da seguinte maneira: na relação do signo consigo mesmo, os signos apresentam-se como quali-signos, sin-signos e legi-signos; na relação com o objeto à que se referem, os signos se apresentam como icones, indices e símbolos, e na relação com o interpretante, apresentam-se como rema, dicente e argumento.

De maneira geral, Peirce define o quali-signo como um signo de pura qualidade; o sin-signo como um signo que se refere a um existente particular; e legi-signo como um signo que é uma lei, uma convenção. Na relação com o objeto - que interessa à pesquisa, em razão de analisarmos existentes particulares -, um ícone é um signo que representa um objeto por ser semelhante a ele. Para Peirce (2012, p.52), "qualquer coisa, seja uma qualidade, um existente individual ou uma lei, é Ícone de qualquer coisa, na medida em que for semelhante a essa coisa e utilizado como um seu signo".

Segundo Santaella (2010, p. 70), o caráter icônico surge a partir de relações de comparação: "São as sugestões que estimulam as comparações". Nesse sentido, como as fotografias impressas em livros didáticos servem para informar, complementando ou acrescentando dados à matéria, elas precisam mostrar semelhanças com uma ideia dada de realidade. Afinal, é importante que o aluno veja a imagem na foto como algo semelhante ao que realmente existe (ou existiu) no mundo.

No entanto, ainda que o caráter icônico da imagem seja importante no processo de compreensão, também é preciso considerar o caráter indicial nas fotografias. A semelhança, nesse caso,

[...] deve-se ao fato de terem sido produzidas em circunstâncias tais que foram fisicamente forçadas a corresponder ponto por ponto à natureza. Sob esse aspecto, então, pertencem à segunda classe dos signos, aqueles que o são por conexão física. (PEIRCE, 2012, p. 65) 
Afinal, os alunos que veem as fotografias impressas nos livros deveriam acreditar que o que está retratado ali corresponde a existentes singulares, partes de uma dada realidade. Aliás, a própria fotografia, em certa medida, é comumente entendida como a representação da realidade, como a constatação de uma coisa ou fato existente. Considerando que as fotografias nos livros tem a função de mostrar que aquilo retratado realmente existe e foi captado por uma tomada fotográfica, o caráter indicial se torna proeminente.

O índice, dessa maneira, deve ser entendido como um tipo de signo que mantém uma relação causal de contiguidade física com o que representa. Para Peirce (2012, p.52), "na medida em que o índice é afetado pelo objeto, tem ele necessariamente alguma qualidade em comum com o objeto, e é com respeito a estas qualidades que ele se refere ao objeto".

Nesse caso, os interpretantes gerados são signos dicentes. Nas palavras de Peirce, um signo dicente é "um signo que, para seu Interpretante, é um Signo de existência real" (2012, p. 53). Peirce ainda afirma que esse é um "tipo de signo que veicula informação, em contraposição ao signo (tal como o ícone) do qual se pode derivar informação" (2012, p. 77). Ou seja, o signo dicente

[...] deve professar referência ou relato a algo como tendo um ser real independentemente de sua representação como tal e, mais, que esta referência ou relação não deve ser apresentada como sendo racional, mas sim surgir como uma Segundidade cega. (PEIRCE, 2012, p. 7778).

Por manter uma relação direta com o objeto que representa, a fotografia tem potencial para indicar um existente. No entanto, esse tipo de signo, como qualquer signo de secundidade, carrega em si signos de primeiridade, quali-signos, signos esses que serão, muitas vezes, os responsáveis por transmitir uma informação. Para Peirce (2012, p. 52), um "Quali-signo é uma qualidade que é um signo. Não pode realmente atuar como signo até que se corporifique; mas esta corporificação nada tem a ver com seu caráter como signo". Nesse sentido, a imagem na fotografia será compreendida em função da crença em que essa guarde alguma semelhança com o objeto que representa. Levando em consideração que essas fotos devem ser didáticas, claras e informativas, o que se espera delas é que os alunos acreditem que tais imagens representem fielmente o que indicam as legendas.

Contudo, é preciso considerar que a produção dessas fotos se baseia em convenções e normas - nos termos de Peirce, legi-signos. Tais convenções são estabelecidas pelos homens em função de uma série de fatores. No caso da definição de imagens para livros didáticos, os signos regidos pelas leis geram índices que atuam em função da iconicidade que existe neles próprios. Em outros termos, são fotos produzidas em função de convenções e leis que visam, através de relações de semelhanças, mostrar algo existente.

Peirce também apresenta outra tríade, a de interpretantes, que será útil ao presente estudo. Santaella define o interpretante como "o efeito interpretativo que o signo produz em uma mente real ou meramente potencial" (2010, p. 23). Os três níveis de intepretantes são: o interpretante imediato, o dinâmico e o final. O primeiro se refere ao potencial interpretativo, interno, do signo. Ainda se trata do nível abstrato, "antes de o signo encontrar um intérprete qualquer em que esse potencial se efetive" (SANTAELLA, 
2010, p. 24). O segundo, o interpretante dinâmico, seria o efeito que o signo produz efetivamente em um intérprete. Nesse caso, é importante também a dimensão psicológica do interpretante, pois o signo pode causar um efeito singular em cada intérprete. $\mathrm{O}$ terceiro nível, interpretante final, refere-se ao resultado interpretativo ao qual todo intérprete chegaria se os interpretantes dinâmicos do signo fossem levados até seu limite. No entanto, isso nunca seria realmente atingível, portanto, os interpretantes serão usados para tentar prospectar como as fotografias são interpretadas pelos alunos que as veem.

Em relação ao potencial que um signo tem para gerar uma interpretação específica (interpretante imediato), o rema é tipo de signo que representa um possível objeto, um signo de possibilidades, uma mera hipótese. De acordo com Peirce (2012, p.53), "todo Rema propiciará, talvez, algumas informações, mas não é interpretado nesse sentido". Por outro lado, o interpretante dicente tem uma relação de existência com o objeto, ele se refere a um fato, um evento, uma ocorrência. O argumento, nessa lógica, é um signo que gera sentido em razão das normas estabelecidas, que envolve o contexto.

$\mathrm{Na}$ análise de um objeto concreto, esses tipos de signos não servem simplesmente como meras classificações, mas sim como padrões que fornecem um método analítico que auxilia no processo de entendimento dos significados que possam ser atribuídos a cada elemento comunicacional. Resguardados por esse arcabouço lógico, entendemos que diferentes fotografias, que ilustram uma mesma matéria, fazem uso de diferentes tipos de signos que dão origens a interpretantes diversos.

Modos de significacã̃o da fotografia nos livros de História

Para compreender o potencial da fotografia como elemento de significação nos livros didáticos, foram selecionadas três fotografias (figura 1) de diferentes edições do livro Saber e Fažer História ${ }^{2}$, para o último ano do Ensino Fundamental, que ilustram parte do conteúdo referente ao governo Collor e ao processo de impeachment ocorrido em 1992. Como exposto anteriormente, partimos da hipótese de que as três fotos podem gerar leituras e entendimentos diferentes.

Figuras 1a; 1b; 1c. Páginas das edições de História dos três anos estudados.
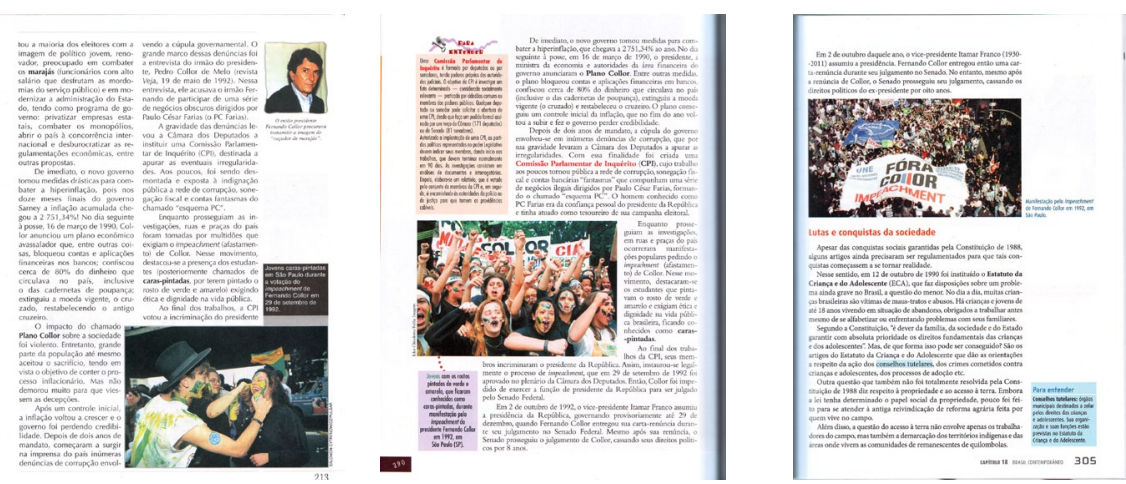

Fonte: Gilberto Cotrim, Editora Saraiva, 1999; 2009; 2012. 


\section{Foto de 1999}

A foto de 1999 (figura 2), publicada na parte inferior direita da página, no tamanho de 11,5 x 8,0 cm, e creditada a Salomon Cytrynoeicz/Pulsar, aparece sob a seguinte legenda: "Jovens caras-pintadas em São Paulo durante a votação do impeachment de Fernando Collor em 29 de setembro de 1992".

Figura 2. Foto da edição de 1999.

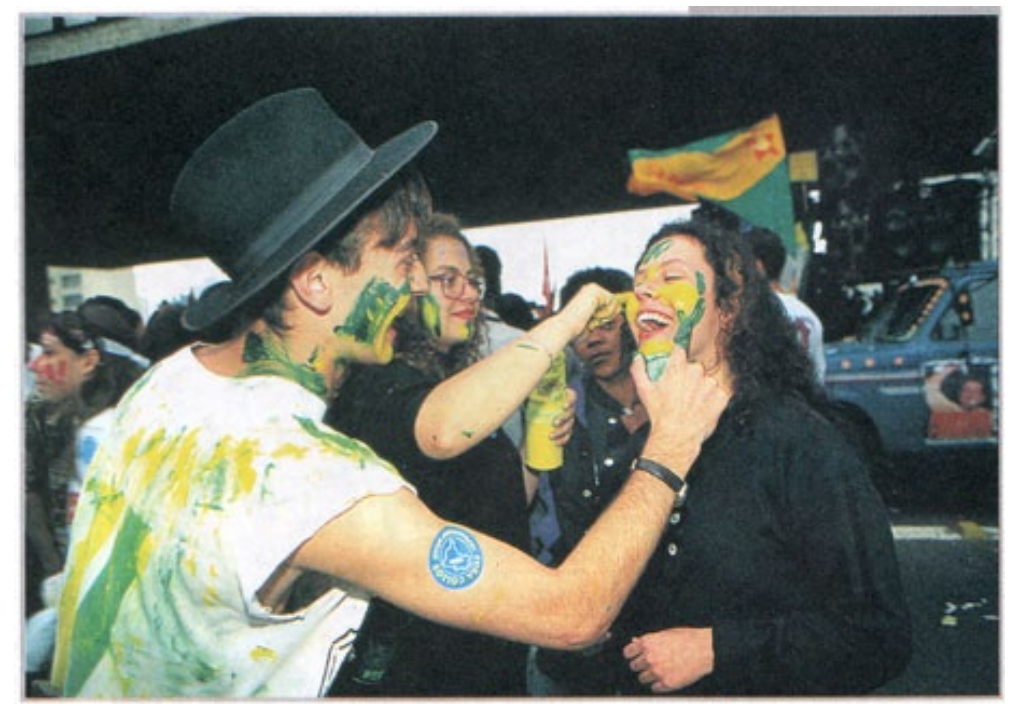

Fonte: Gilberto Cotrim. Saber e Fazer História: História Geral e do Brasil. $8^{\mathrm{a}}$ série, 1999. Editora Saraiva.

Em primeiro plano, exibem-se dois jovens sorridentes pintandose com tinta verde e amarela. O rapaz traz no braço um adesivo azul com o mapa do Brasil em que é possível ler: "Fora Collor". Existe uma relação entre os jovens no primeiro plano e o contexto que os rodeia: uma moça de perfil, à esquerda da foto, com o rosto pintado com tinta vermelha e uma faixa na cabeça, indicando fazer parte da manifestação; ao fundo, um veículo com bandeiras e lâmpadas e um viaduto que sugerem que a foto foi tirada na rua. A legenda sobre a foto acrescenta informações à imagem e ambos complementam a matéria, que explica quem foram os "caras-pintadas" - o termo é destacado em negrito no texto.

Por meio da foto e da legenda é possível entender que esses jovens na foto faziam parte dos chamados “caras-pintadas". No entanto, não é possível ver na figura a multidões a que se refere o texto:

[...] ruas e praças do país foram tomadas por multidões que exigiam o impeachment (afastamento) de Collor. Nesse movimento, destacouse a presença dos estudantes (posteriormente chamados de caraspintadas, por terem pintado o rosto de verde e amarelo) exigindo ética e dignidade na vida pública.

Considerando o potencial de sentido existente em qualquer signo, 
podemos afirmar que há na representação o potencial de significar que os jovens estão se preparando para participar das manifestações mencionadas. Assim, podemos supor que, a partir da fotografia e dos textos, os estudantes tenham dados suficientes para entender como os jovens participaram da manifestação em 1992. Como registro de um fato, a fotografia, nessa publicação, visa demonstrar isso. Esse aspecto do registro fotográfico se deve ao predomínio do signo indicial, um tipo de signo que possui alguma qualidade do objeto por ser realmente afetado por esse objeto. Ou seja, tal imagem tem o potencial de gerar nos estudantes um interpretante dicente, um signo que representa um fato, um evento, uma ocorrência.

No Nível de Secundidade, o dicente (ou dici-signo ou fema ou quase proposição) é um signo que será interpretado pelo seu interpretante final como propondo e veiculando alguma informação sobre um existente [...]. O meio mais fácil de reconhecer o dicente é saber que ele ou é verdadeiro ou é falso, mas em contraposição ao argumento, o dicente não nos fornece razões por que é falso ou verdadeiro. Ele é um signo puramente referencial, reportando-se a algo existente. Desse modo, seu interpretante terá uma relação existencial, real com o objeto do dicente, tal como este mesmo tem. (SANTAELLA, 1995, p.190)

Em outros termos, provavelmente os estudantes julgam tal fotografia como demonstração real dos acontecimentos, uma vez que acreditam que o fotógrafo esteve ali registrando o momento - a legenda traz também informações sobre a data em que a fotografia foi tirada.

Além do caráter predominantemente indicial (de registro físico) o aspecto icônico também é de fundamental importância, pois procura mostrar aos estudantes, através da semelhança, como eram os caras-pintadas e o contexto em que estavam inseridos. Conforme lembra Peirce, todo signo indicial envolve uma espécie de ícone, um tipo de signo que representa um objeto por ser semelhante a ele. Graças a essa relação de semelhança, o ícone pode substituir a coisa que representa.

Contudo, ainda que os estudantes consigam apreender como os caras-pintadas participaram da manifestação política, não é possível, a partir da fotografia, afirmar a dimensão das manifestações ou da multidão que participou. Assim como também não há informações sobre grupos que foram atuantes nessas manifestações (organizações estudantis, trabalhistas etc.) - como poderemos observar, a fotografia da edição de 2012 prioriza tais informações em detrimento à imagem dos caras-pintadas. 
Foto de 2009

A fotografia da edição de 2009 (Figura 3) tem dimensões de 11,7 x $8 \mathrm{~cm}$. Nesta edição, o texto do livro aparece em uma só coluna principal e com textos complementares à margem. Neste espaço, há um quadro intitulado "Para entender", com fundo em cor salmão, explicando o que é uma "Comissão Parlamentar de Inquérito" (Figura 1b).

A fotografia, creditada a Eder Chiodetto/Folha Imagem, ocupa parte da mancha e a margem da página e tem a seguinte legenda: "Jovens com os rostos pintados de verde e amarelo, que ficaram conhecidos como caraspintadas, durante manifestação pelo impeachment do presidente Fernando Collor em 1992, em São Paulo (SP)". Na legenda, a palavra "Jovens" está destacada em verde.

$\mathrm{Na}$ foto que se apresenta como objeto de análise, jovens fazem movimentos de protesto com os braços. Boa parte das pessoas vestem roupas pretas e usam bandanas brancas, nas quais podemos identificar a palavra "justiça”. Ao fundo, veem-se diversas faixas e bandeiras cujo conteúdo não é possível ler, mas aparentando se tratar de uma manifestação. É possível também perceber a presença de árvores mais ao fundo, o que indica se tratar de um ambiente externo.

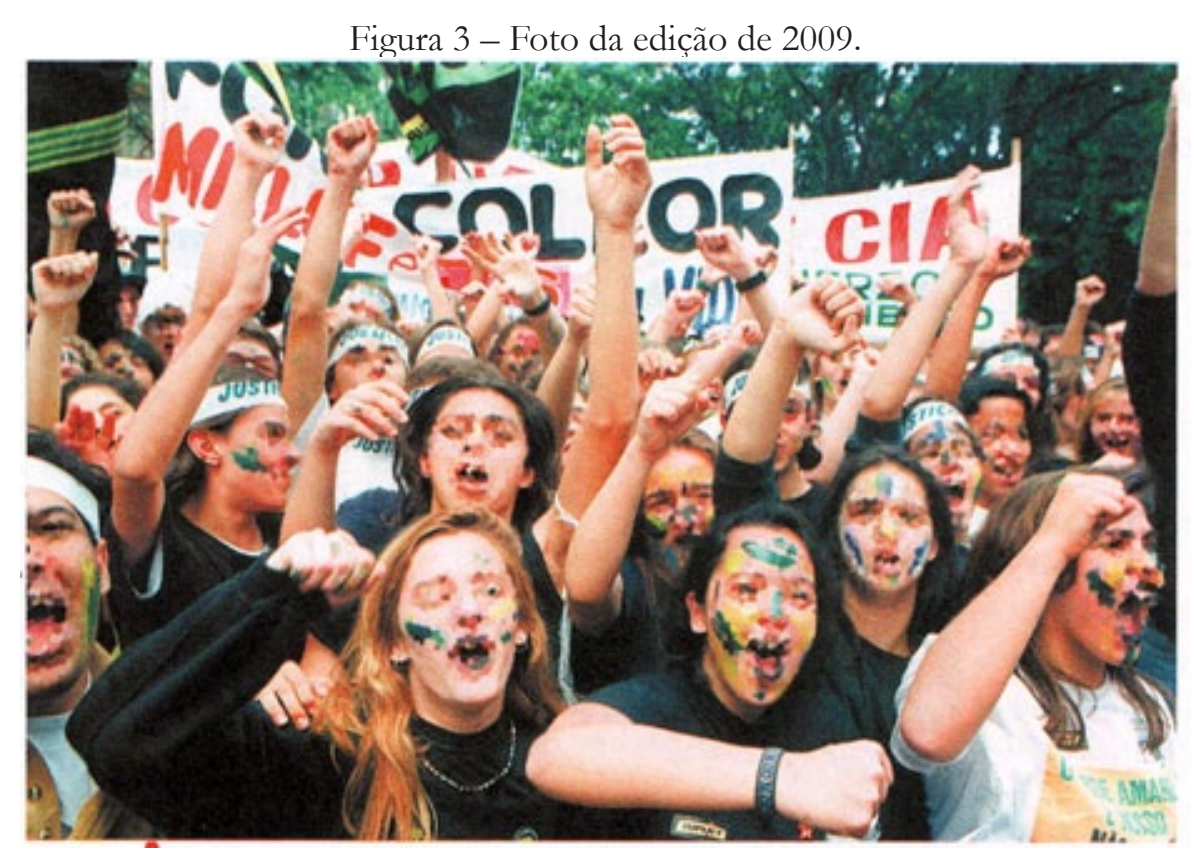

Fonte: Gilberto Cotrim e Jaime Rodrigues. Saber e Fazer História, $9^{\circ}$ ano. São Paulo, Editora Saraiva, 2012.

Nesta fotografia, nota-se que foi realizada uma distorção na imagem: os rostos das pessoas que estão em primeiro plano aparecem "pixelizadas",

1 Pixels são blocos de cores que constituem uma imagem digital. Ao aumentar 
o que faz com que as faces dos retratados não fiquem nítidas (Figura 4). No entanto, o efeito apresenta "baixa pixelização", o que faz com que os rostos não fiquem totalmente desfigurados. A distorção provocada nos rostos das pessoas retratadas se deve a uma intervenção proposital durante a edição do livro, que traremos em breve.

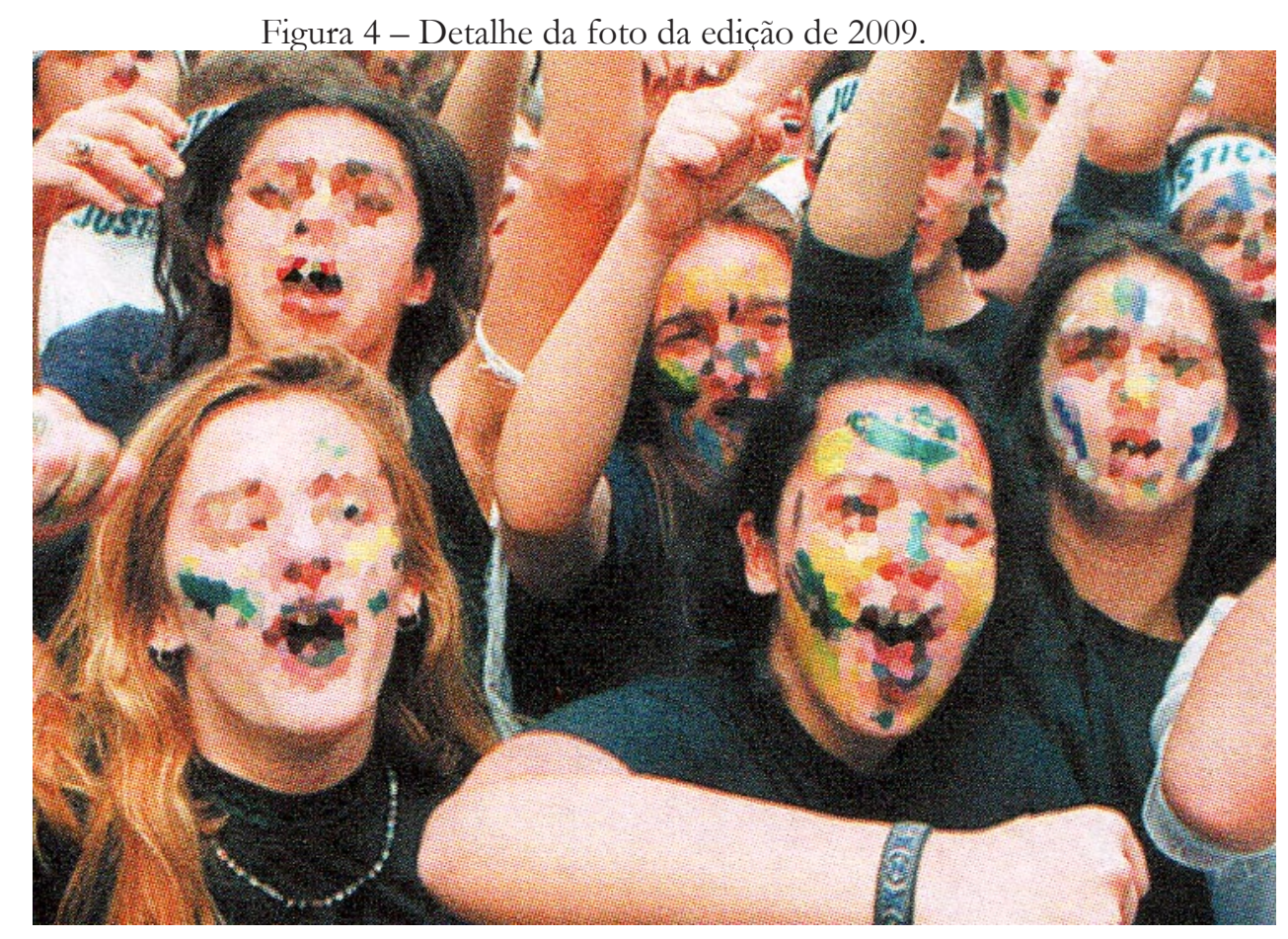

Fonte: Gilberto Cotrim e Jaime Rodrigues. Saber e Faz̧er História, $9^{\circ}$ ano. São Paulo, Editora Saraiva, 2012.

A "baixa pixelização" na foto impede o reconhecimento pleno dos rostos, mas permite perceber não somente que são rostos de pessoas jovens como também observar em detalhe o tipo de pintura facial que eles utilizaram (cores e traços). Desse modo, apesar da interferência do recurso digital, o aluno tem condições de ver alguns manifestantes. É possível reconhecer pessoas jovens participando de uma manifestação, com faixas nas cabeças, braços levantados, bocas abertas como que gritando e, ao fundo, faixas com frases em preto, vermelho, azul, reafirmam ser uma manifestação. Pela continuidade, podemos deduzir que a foto mostra apenas uma parte dos manifestantes, pois nas laterais da imagem, vemos as imagens das pessoas "cortadas" - por exemplo, um braço levantado à direita e meio rosto de um rapaz à esquerda. Diferente da foto anterior, esta sugere que diversos jovens, parte de uma multidão, participaram dos protestos.

Como na edição anterior, a legenda serve para complementar a informação sobre os caras-pintadas, mencionados e destacados no texto, e

bastante uma imagem digital, é possível ver os pixels individuais, o que caracteriza a pixelização. 
acrescentar dados sobre o local e data da manifestação.

Ao ver a imagem, os estudantes podem confirmar, novamente em razão do predomínio do signo indicial, que os caras-pintadas pintavam os rostos e eram jovens que participaram das manifestações. Assim como na foto de 1999, não é possível perceber o volume de pessoas que participou do protesto, mas a foto permite ter uma ideia melhor da multidão do que a anterior.

Figura 5 - Fotos das edições de 1999 e 2009.

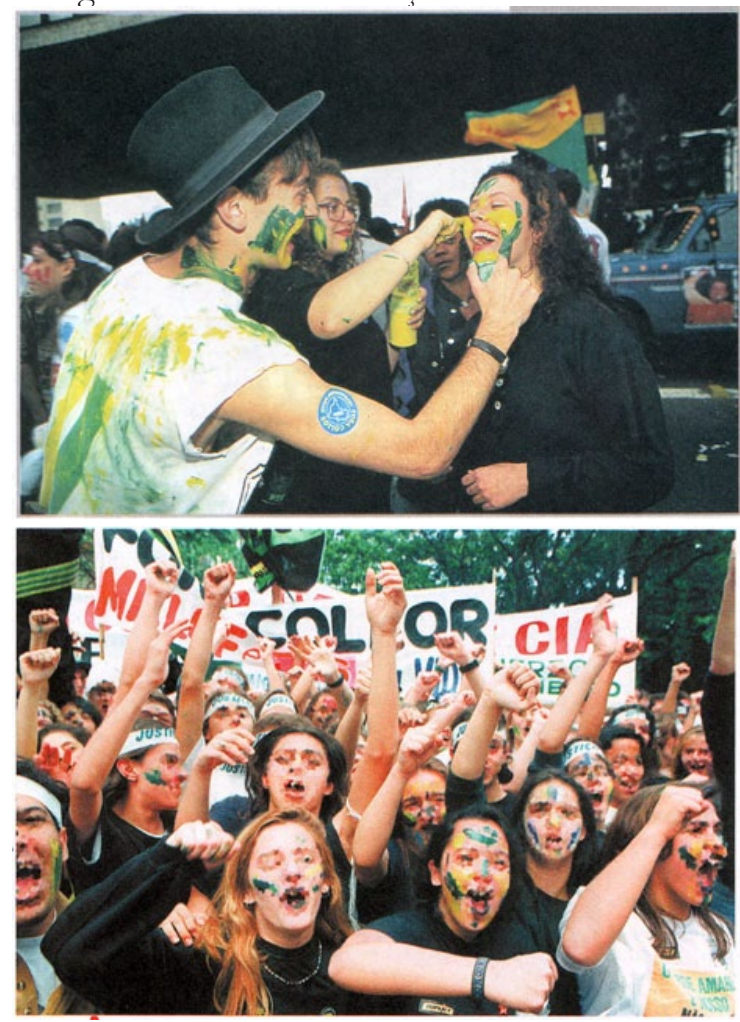

Fonte: Livros de História, Editora Saraiva.

O uso do recurso da pixelização (convenção utilizada pelas indústrias gráfica e audiovisual para preservar a imagem das pessoas retratadas) na edição de 2009, deve-se à lei no 9.610, de 19 de fevereiro de 1998, que versa sobre os direitos autorais no Brasil e alterou certas práticas de produção de imagens para livros didáticos. Esta lei passou a ser aplicada nas publicações e reproduções de obras literárias, artísticas e científicas, afetando também o conteúdo do material didático. O uso de imagens de pessoas em ilustrações de livros didáticos, como exposto anteriormente, foi afetado também pelo atual Código Civil (Lei no 10.406 de 10 de janeiro de 2002), que, no Capítulo 2, aborda a questão do direito à imagem ("Dos Direitos da personalidade"). O Artigo 20 do Código Civil aborda tanto os direitos autorais quanto os de personalidade:

Salvo se autorizadas, ou se necessárias à administração da justiça ou à manutenção da ordem pública, a divulgação de escritos, a transmissão da palavra, ou a publicação, a exposição ou a utilização da imagem de 
uma pessoa poderão ser proibidas, a seu requerimento e sem prejuízo da indenização cabível, se lhe atingirem a honra, a boa fama ou a respeitabilidade, ou se destinarem a fins comerciais.

Apesar de se tratar de uma manifestação pública, a editora deveria ter a autorização dos retratados para reproduzir essa foto no livro, o que seria difícil de obter pelo número de pessoas retratadas. Portanto, foi feita a opção de interferir na imagem.

Considerando que muitas vezes a fotografia é vista apenas como uma mera ilustração, e considerando ainda a técnica utilizada para pixelizar a fotografia - em que se pode identificar certos traços de expressão -, acreditamos que boa parte dos estudantes não tenha sequer percebido a interferência. O reconhecimento de signos convencionais, legi-signos, passa obrigatoriamente pelo conhecimento das regras que regem tais signos.

Ou seja, para entender porque os rostos são apresentados de maneira distorcida, os estudantes precisariam compreender as convenções gráficas utilizadas para impedir a identificação do rosto de uma pessoa e ter o conhecimento das leis que motivam o uso de tais recursos técnicos. Em razão disso, acreditamos que mesmo os estudantes que perceberam, mas não questionaram o professor sobre a interferência, tenham acreditado ser uma falha de impressão.

\section{Foło de 2012}

A fotografia da edição de 2012 (Figura 6) tem dimensões de 12,5 x 7 $\mathrm{cm}$. Ela não apresenta o crédito ao lado da foto, como nos casos anteriores, mas podemos encontrá-lo ao final do livro nas páginas de créditos: Epitácio Pessoa/AE.

Figura 6 - Página 305 do livro Saber e Fazer História, 9ª ano.

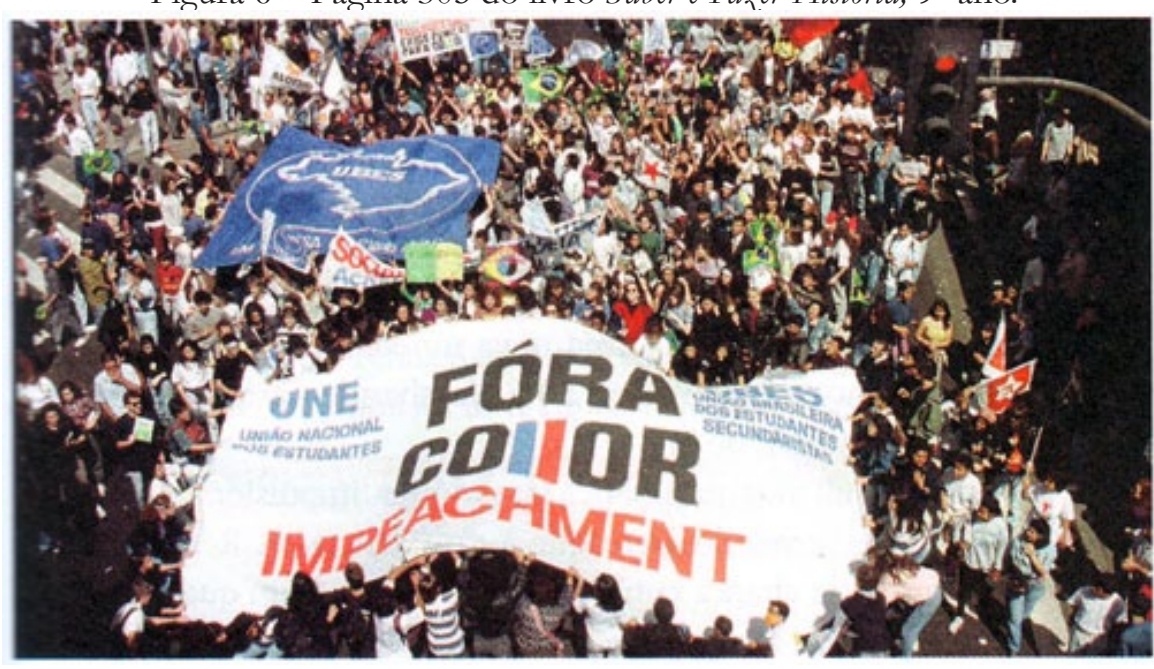

Fonte: Gilberto Cotrim e Jaime Rodrigues. Saber e Fazer História, 9 ano. São Paulo: Editora Saraiva, 2012. 
O texto nesta edição encontra-se em uma só coluna, tendo às margens quadros explicativos complementares (Figura 1c). Nesta página há à margem direita um quadro em azul intitulado "Para entender" que explica o que são "conselhos tutelares", termo que está em destaque no texto. Na legenda da foto está escrito: "Manifestação pelo impeachment de Fernando Collor em 1992, em São Paulo”.

Esta imagem foi fotografada a partir de uma vista aérea, uma vez que mostra uma multidão na rua carregando cartazes e bandeiras durante uma manifestação. Em destaque aparece um grande cartaz no qual se lê a mensagem "Fóra Collor Impeachment" [sic]. No canto superior direito se pode ver um semáforo com a cor vermelha acesa e uma faixa de pedestres no canto superior esquerdo, o que indica o local do evento: uma rua ou avenida larga. Entre a multidão é possível ver bandeiras diversas, como as do Brasil, do PT (Partido dos Trabalhadores), da UNE (União Nacional dos Estudantes), entre outras.

Considerando-se o aspecto indicial do signo, como registro de um fato, podemos compreender que se tratou de uma manifestação pública, que ocorreu em local público e interferiu no cotidiano da cidade. Por outro lado, considerando o aspecto simbólico, percebe-se que a manifestação reuniu entidades políticas e estudantis que visavam interferir diretamente na rotina da cidade (estão em uma grande avenida da cidade de São Paulo) para chamar a atenção dos diversos setores sociais. Os símbolos não guardam qualquer relação de semelhança ou contiguidade com o objeto, a relação é puramente convencional. Para compreender um símbolo, é necessário entender o seu contexto.

Assim, os logotipos dessas entidades, sob a óptica da semiótica peirciana, funcionam como legi-signos, pois são convenções reconhecidas por aqueles que conhecem os sentidos de seus elementos de configuração.

No que se refere aos potenciais interpretantes gerados (interpretante imediato), os estudantes podem ver na foto o teor da manifestação, ter ideia da multidão que saiu às ruas para protestar contra o presidente. No entanto, os estudantes que tiveram acesso a esta edição, se não tiverem conhecimento prévio sobre esses acontecimentos (a experiência colateral, nos termos de Peirce), não saberão quem foram os caras-pintadas e nem como eles eram (ou por que eram chamados desse modo). Aliás, o texto desta edição sequer menciona o termo "caras-pintadas".

Observando novamente as três fotos analisadas (Figuras 1a; 1b; 1c), percebemos que elas parecem formar um movimento de "distanciamento" do intérprete, no sentido de que a primeira mostra pessoas em plano próximo, em destaque; a segunda apresenta diversas pessoas ainda próximas da câmera, 
mas em um plano mais aberto; e a terceira, uma multidão em uma foto aérea.

A foto de 1999 mostra com clareza os rostos dos caras-pintadas e é possível perceber nela o "clima" da pré-manifestação - jovens sorrindo, se pintando, bandeira ao fundo, pessoas se movimentando - e algumas indicações de que se trata de um ambiente urbano público. No entanto, não é possível apreender a partir dela a dimensão da manifestação ou o impacto que ela teve na cidade. Na foto de 2009 é possível ver tanto os caras-pintadas quanto uma parte da manifestação. Embora haja a interferência nos rostos das pessoas, é possível ver como esses jovens se pintaram e ter uma ideia de como foi a manifestação, o ato de protesto, através dos movimentos dos braços, das expressões de pessoas gritando, das faixas carregadas pela multidão. Na foto de 2012, já não é mais possível ter acesso a informação alguma sobre os caras-pintadas - que sequer são mencionados na legenda ou no texto. No entanto, nesta foto é possível verificar que a manifestação reuniu muita gente, entidades escolares e políticas, para protestar contra o presidente da República em uma grande avenida de São Paulo. Tudo indica que a foto da edição de 2012 apresenta a "solução" encontrada pela editora para atender às leis de direito de imagem: a foto é distante, mostra a multidão, os cartazes, mas sem destacar nenhuma pessoa. Ela, portanto, demonstra uma realidade sob um ângulo diferente das anteriores.

\section{Consideracões Finais}

Como se pôde observar, a foto publicada na década de 1990 foi produzida na época das mudanças nas leis de direito autoral e de direito à imagem, período em que o governo começou a realizar a avaliação dos livros inscritos no PNLD (Programa Nacional do Livro Didático) e passou a estabelecer critérios de qualidade, além de criar os parâmetros curriculares. Desse modo, tal foto não foi afetada diretamente pelas leis que estavam sendo implantadas. Como nessa década ainda estava iniciando o uso da internet, essa imagem provavelmente foi um primeiro contato de muitos estudantes com as manifestações do impeachment. No processo de significação, os potenciais indiciais servem para comprovar que aqueles jovens participaram das manifestações e os potenciais icônicos sugerem que eles seriam os caraspintadas. A fotografia seguinte apresenta características diferentes, que indicam a preocupação da editora em atender à legislação vigente. No entanto, o uso de recursos de computação gráfica prejudicaram a representação dos caras-pintadas. É verdade que a fotografia ainda consegue transmitir alguma informação sobre esses jovens, mas não de forma plena. Na terceira foto, apresenta-se uma nova situação: o Plano Geral evita que a representação mostre os rostos das pessoas que estão em cena. A imagem aérea transmite 
outro ponto de vista sobre as manifestações no período.

Considerando que as fotografias em livros escolares devem ser didáticas, claras e informativas, espera-se que os estudantes acreditem que elas retratem a realidade - neste caso, manifestações ocorridas durante o processo de impeachment do presidente Collor em 1992. Ou seja, a fotografia da edição de 1999 pode levar o estudante a crer que os jovens retratados eram os caraspintadas que se preparavam para as manifestações pró impeachment, a foto de 2009 possibilita ao estudante compreender a maneira como os caras-pintadas se comportavam durante as manifestações; e a foto de 2012 demonstra como as manifestações ocuparam as ruas. Ou seja, cada uma delas, no processo de comunicação, tem o potencial de fornecer ao estudante parte das informações sobre os acontecimentos. Mas apenas parte. 


\section{Referências}

COSTA, Cristina. Educação, Imagem e Mídias. São Paulo: Cortez, 2013.

(Coleção Aprender e Ensinar com Textos, v. 12/ coord. geral Ligia Chiappini).

PEIRCE, Charles Sanders. Semiótica. São Paulo: Perspectiva, 2012. SANTAELLA, Lucia. Semiótica Aplicada. São Paulo: Cengage Learning, 2010.

Documentos analisados

COTRIM, Gilberto. Saber e Fazer História $8^{a}$ série: História Geral e do Brasil. São Paulo: Editora Saraiva, 1999.

; RODRIGUES, Jaime. Saber e Fazer História $9^{\circ}$ ano: Mundo contemporâneo e Brasil república. 6. ed. São Paulo: Editora Saraiva, 2009.

; ___ Saber e Fazer História $8^{\circ}$ ano: 7. ed. São Paulo: Editora Saraiva, 2012.

Notas

1 Existem também outros fatores que afetam diretamente o trabalho iconográfico, como, por exemplo, a proposta pedagógica ou concepção editorial, mas entendemos que as alterações ocorridas nesses períodos, como se poderá observar nas publicações analisadas, foram principalmente motivadas pelas limitações impostas pelas leis de direitos autorais e pelo Código Civil.

2 As três edições são de autoria de Gilberto Cotrim, publicados pela Editora Saraiva nos anos de 1999, 2009 e 2012. 